\title{
Judgments of duration, figure-ground contrast, and size for words and nonwords
}

\author{
ROLF REBER \\ University of Bergen, Bergen, Norway \\ and \\ THOMAS D. ZIMMERMANN and PASCAL WURTZ \\ University of Bern, Bern, Switzerland
}

\begin{abstract}
Does the word-superiority effect on letter discrimination result in a word-superiority effect on duration judgments? We examined this question in five experiments. In the first four experiments, we have demonstrated that (1) words shown for 32-80 msec were judged as presented longer than nonwords shown for the same duration; (2) this word-superiority effect persists if the stimuli are shown for an objective duration of up to $250 \mathrm{msec}$; and (3) these effects can be extended to judgments of figure-ground contrast and letter size. These findings extend existing data on effects of processing fluency on perceptual judgments. In Experiment 5, we found that duration judgments were higher for words than for pronounceable nonwords, and duration judgments were higher for pronounceable nonwords than for nonpronounceable nonwords. We discuss the implications of this finding for the discrepancy-attribution hypothesis (Whittlesea \& Williams, 1998, 2000, 2001).
\end{abstract}

Does phenomenal experience of a stimulus reflect the qualities of its processing? Reicher (1969) has shown that words are processed faster than nonwords. Specifically, he presented four-letter words, four-letter nonwords, and single letters very briefly. He then presented two letters and asked participants which of the two letters had appeared before. Participants showed higher performance for words than for nonwords and single letters, as reflected by higher accuracy and faster reaction times. In this article, we are interested in the performance difference between words and nonwords, an effect that is well established (see, e.g., Prinzmetal \& Silvers, 1994); we are not interested in the performance difference between words and single letters. A word-superiority effect on letter discrimination indicates faster processing of words than of nonwords. In this article, we examine whether this faster processing of words may translate into a phenomenal experience of longer duration, higher figure-ground contrast, and larger size.

There is much evidence that more-familiar stimuli are judged to be presented longer than less-familiar stimuli. For example, Warm and McCray (1969; see Allan, 1979, for further findings) have found that frequently used

This research was supported by the L. Meltzer Foundation at the University of Bergen and Swiss National Science Foundation Grant 6157881.99 to R.R. We thank Deanne Westerman and Bruce Whittlesea for comments on an earlier version of the manuscript. Correspondence concerning this article should be addressed to R. Reber, University of Bergen, Department of Psychology, Christiesgate 12, N-5015 Bergen, Norway (e-mail: rolf.reber@psysp.uib.no).

Note-This article was accepted by the previous editorial team, headed by Neil Macmillan. words presented for $1 \mathrm{sec}$ were judged as shown longer than infrequently used words shown for the same duration. Witherspoon and Allan (1985) found that participants judged more familiar stimuli to be presented longer than unfamiliar stimuli. These findings are relevant to the studies presented here because one basis of familiarity is perceptual fluency (e.g., Whittlesea, 1993; Whittlesea, Jacoby, \& Girard, 1990), which is the ease with which incoming information can be processed (for a detailed discussion, see Reber, Wurtz, \& Zimmermann, 2004; Winkielman, Schwarz, Fazendeiro, \& Reber, 2003).

There is abundant evidence for the impact of processing fluency on several kinds of judgments, such as those of recognition (Jacoby \& Dallas, 1981; Whittlesea, 1993), affective preference (Reber, Winkielman, \& Schwarz, 1998; Whittlesea, 1993), fame (Jacoby, Kelley, Brown, \& Jasechko, 1989), truth (Begg, Anas, \& Farinacci, 1992; Reber \& Schwarz, 1999), ease of performance (Kelley \& Jacoby, 1996), normative word frequency (Toth \& Daniels, 2002), stimulus duration (Masson \& Caldwell, 1998; Witherspoon \& Allan, 1985), and stimulus clarity (Goldinger, Kleider, \& Shelley, 1999; Jacoby, Allan, Collins, \& Larwill, 1988; Whittlesea et al., 1990). Most of these studies used stimulus repetition to manipulate processing fluency, with some exceptions. In a study by Whittlesea (1993, Experiment 6), for example, people had to judge whether a target word that had been shown before was presented for a short duration $(67 \mathrm{msec})$ or for a long duration $(134 \mathrm{msec})$. Before the judgment, a list of words was presented briefly, including the target word that appeared for the long duration in half of the trials and for the short duration in the other half of the trials. 
When the target words appeared, participants had to pronounce them, and pronunciation latency as an indicator of perceptual fluency was measured. Whittlesea found that target words shown for $134 \mathrm{msec}$ were pronounced faster than words presented for $67 \mathrm{msec}$. Orthogonally to presentation duration, masking density was manipulated, and light masking led to faster word identification than did heavy masking. There were thus two independent sources of perceptual fluency: presentation duration and masking density. Whittlesea found that participants relied on both presentation duration and masking density in judging the presentation duration of a word. Judged duration was higher for words shown longer and, more important, for words shown with light masking. This finding suggests that participants used perceptual fluency, regardless of the source of this feeling. They were not able to distinguish between the relevant source (presentation duration) and the irrelevant source of fluency (masking density).

The theoretical implications of these findings are straightforward: When people can process a stimulus $A$ more fluently than a stimulus $B$, they are expected to have a richer phenomenal experience of stimulus $A$ than of stimulus $B$. When asked to judge the presentation duration of stimuli, participants judge stimulus $A$ to be presented longer than stimulus $B$ when both stimuli are shown for the same duration. Because words are processed more fluently than nonwords (Reicher, 1969), one would predict that the apparent duration of words is longer than the apparent duration of nonwords shown for the same objective duration.

Empirical evidence for this prediction is somewhat mixed. In several experiments, Avant and colleagues (Avant \& Lyman, 1975; Avant, Lyman, \& Antes, 1975) have shown that the judged duration for a nonword presented for $30 \mathrm{msec}$ is longer than the same judgment for a word presented for the same duration, contradicting the notion that facilitated processing of familiar stimuli result in higher perceived duration. In a similar study, however, Thomas and Weaver (1975) found that a letter string was perceived as shown longer than a blank field, but there was no difference between words and nonwords composed of the same letter materials. Thomas and Weaver presented the stimuli for 40 or $80 \mathrm{msec}$.

Reingold and Merikle (1988) replicated the study of Avant et al. (1975) and did not find a difference between words and nonwords for presentation duration of $33 \mathrm{msec}$; this replicated the finding by Thomas and Weaver (1975). However, words presented for 50 and $67 \mathrm{msec}$ were judged to be shown longer than nonwords shown with identical presentation durations, contradicting the findings of Avant et al. and those from the 80-msec presentation condition of Thomas and Weaver.

In the present article, we extend existing knowledge in several ways: In Experiment 1, we found further evidence for a word-superiority effect on duration judgments for objective durations between 32 and $80 \mathrm{msec}$, bolstering the findings of Reingold and Merikle (1988). In Experiment 2, we examined duration judgments for words and nonwords when objective durations were between 100 and $250 \mathrm{msec}$. These are longer durations than those used by Reicher (1969), Avant et al. (1975), and Reingold and Merikle (1988). Prinzmetal (1992; Prinzmetal \& Silvers, 1994) found word-superiority effects on letter discrimination for longer presentations, and a perceptual fluency account predicts that the wordsuperiority effect can be observed when stimuli are presented longer. We examined the word-superiority effect for judgments of figure-ground contrast in Experiment 3 and for judgments of letter size in Experiment 4. Again, we tested both short- $(32-80 \mathrm{msec})$ and long-objective durations (100-250 msec). In Experiments 1 to 4, we used nonwords that were orthographically irregular and difficult to process.

In Experiment 5, we added more orthographically regular nonwords to the stimuli in order to test the discrepancyattribution hypothesis (Whittlesea \& Williams, 1998, 2000, 2001) for duration judgments. According to this hypothesis, perceptual fluency is attributed to the judgment at hand only if there is a discrepancy between expected fluency and actual fluency. Whittlesea and Williams have found that there were more false alarms to regular nonwords than to both words and irregular nonwords. Presumably, the actual fluency of perceiving regular nonwords was higher than participants expected; therefore, they attributed this unexpected fluency to familiarity with the word and gave a positive recognition judgment.

\section{EXPERIMENT 1}

\section{Method}

Sixteen students of a Swiss university participated in this experiment for partial course credit. All reported normal or corrected-tonormal vision. The experiments were programmed with PsyScope Version 1.2.5 (Cohen, MacWhinney, Flatt, \& Provost, 1993) and run individually on Power Macintosh computers, with a 15 -in. color monitor running at $60 \mathrm{~Hz}$.

Materials. The stimuli used in this experiment were 96 German nouns of three to eight letters $(M=5.67, S D=1.10$ for letters and $M=1.77, S D=.49$ for syllables on average). We selected words that spanned the whole range of spoken word frequency and concreteness. Their mean percentage in spoken German according to Ruoff (1981) was .058 ( $S D=.15)$; their mean concreteness, as rated on a scale from -20 to +20 (see Hager \& Hasselhorn, 1994), was $5.87(S D=9.09)$. From these words, we generated 96 nonwords by rearrangement of the letters; these nonwords did not correspond to German orthographic rules and were thus more difficult to read.

Procedure. The participants were seated approximately $70 \mathrm{~cm}$ from the computer screen and responded by pressing a number key (1-9) on the keyboard. After the instructions, the participants were given practice trials that were not included in data analysis. These trials consisted of two examples of the highest and lowest presentation duration in order to set reference points for the judgments to be made in the test phase of the experiment. Eight subsequent practice trials followed, with one word and one nonword in each duration condition, before the participants got the 96 test words and 96 nonwords in random order.

First, a white fixation cross appeared on a black background for $500 \mathrm{msec}$ in order to focus the participants' attention on the center of the screen. Then, the 24-point target item followed (word or non- 
word). Presentation durations were $32,48,64$, and $80 \mathrm{msec}$. The participants had to judge how long the target items were visible on a 9-point scale ranging from 1 (short) to 9 (long). Each of the 192 target items was presented only once and was immediately masked by a random dot pattern ( $80 \%$ white and $20 \%$ black pixels) $5 \mathrm{~cm}$ wide $\times 1.5 \mathrm{~cm}$ high. The mask remained until the participants gave a duration judgment by pressing a key from 1 to 9 . The conditions (duration and type) were completely balanced across the 192 trials.

Statistical analysis. The experimental setup resulted in a twofactorial design, with the first factor being the four stimulus duration conditions that the participants had to judge. The second factor was stimulus type, either word or nonword. We report the within-subjects repeated contrasts for objective duration, comparing Level 1 ( $32 \mathrm{msec})$ with Level 2 (48 $\mathrm{msec}$ ), Level 2 with Level 3 (64 msec), and Level 3 with Level 4 ( $80 \mathrm{msec})$, and simple contrasts for stimulus type (word vs. nonword). ${ }^{1}$

Finally, we report the interaction between duration and stimulus type in order to examine the finding of Reingold and Merikle (1988) that there was no difference in judgments between words and nonwords when presentation duration was short.

\section{Results and Discussion}

Means, standard deviations, mean comparisons between words and nonwords, and estimates of effect size are shown in Table 1.

As outlined above, we performed an analysis of variance (ANOVA) with objective duration (32 vs. $48 \mathrm{msec}$, 48 vs. $64 \mathrm{msec}$, and 64 vs. $80 \mathrm{msec}$ ) and stimulus type (word vs. nonword) as the two independent variables.

Duration judgments increased with increasing presentation duration, as expressed by significant differences between subsequent levels of presentation duration [all $F_{\mathrm{s}}(1,15)>11.20$, all $\left.p \mathrm{~s}<.005\right]$. More important, the participants judged words to be presented longer than nonwords, as shown by the stimulus type main effect $[F(1,15)=18.86, p=.001]$. This finding replicated the word-superiority effect found by Reingold and Merikle (1988) and contradicted the findings of Avant et al. (1975). Our finding suggests that faster processing of the words resulted in a feeling of higher fluency that was attributed to duration of stimulus presentation.

The two-way interactions between duration and stimulus type were not significant for the three contrasts $[F \mathrm{~s}(1,15)<2.86]$. In contrast to the findings of Reingold and Merikle (1988), we obtained a word-superiority effect on duration judgments when the objective duration was $32 \mathrm{msec}$. As the rightmost column in Table 1 shows, the effect size for the word-nonword difference was smallest when stimuli were presented for $32 \mathrm{msec}$,

Table 1

Means and Standard Deviations for Duration Ratings for Words and Nonwords, $t$ Values and Error Probabilities, and Effect Size $\boldsymbol{r}$ for Each Exposure Duration Condition

\begin{tabular}{ccccccccc}
\hline \multirow{2}{*}{$\begin{array}{c}\text { Time } \\
\text { (in msec) }\end{array}$} & \multicolumn{2}{c}{ Word } & & \multicolumn{2}{c}{ Nonword } & & & \\
\cline { 2 - 3 } \cline { 5 - 7 } & $M$ & $S D$ & & $M$ & $S D$ & $t$ & $p$ & $r$ \\
\hline 32 & 3.54 & .85 & 2.96 & .78 & 3.28 & .005 & .646 \\
48 & 4.40 & .98 & & 3.41 & .64 & 3.38 & .004 & .658 \\
64 & 5.52 & .84 & 4.55 & .67 & 4.24 & $<.001$ & .738 \\
80 & 6.15 & .94 & 5.07 & 1.13 & 3.73 & .002 & .694 \\
\hline
\end{tabular}

Note- $d f=15$. but the increase in differences was not linear with increasing level of objective duration.

In this first experiment, participants judged words to be presented for a longer duration than that for nonwords. Importantly, participants judged words to be presented longer than nonwords even when objective duration was $32 \mathrm{msec}$. The interaction between duration and type failed to be significant for all three contrasts.

\section{EXPERIMENT 2}

In this experiment, we examined further the wordsuperiority effect on duration judgments. We added a long-duration condition in which stimuli were shown for $100-250 \mathrm{msec}$. By manipulating presentation condition, we were able to examine whether there would be a wordsuperiority effect on duration judgments when objective duration increased. Moreover, we tried to answer another question. Participants in the Reingold and Merikle (1988) study did not show any difference in judged durations of words and nonwords when the objective presentation duration was $32 \mathrm{msec}$. This could mean that participants might indeed not see any difference in subjective duration when exposure duration was very short. However, there was an alternative possibility: Participants first had to adapt to the duration range. They then compared the duration of a presented stimulus to this adaptation level, judging duration of a stimulus as relatively short when it was below this level and relatively long when it was above adaptation level (see Helson, 1964). An ideal participant would give a judgment of zero duration if objective duration was zero. If duration judgments then increased with the increase in objective duration, the differences in judgments would increase with increasing duration. Effects of range of duration, combined with the increase in duration estimates, might therefore result in lower differences at the lower end of the range used in an experiment, independent of exposure duration. This assumption holds for linear as well as for exponential increases if the intercept and the exponent of $x$ are identical and only the coefficient is different. In sum, we examined the word-superiority effect for longer durations and the more technical issue of adaptation to certain frames of reference; the latter question has consequences for the interpretation of duration judgment data.

\section{Method}

Participants. Forty students of a Swiss community college participated in this experiment, 20 in the short-duration condition, and 20 in the long-duration condition. All reported normal or correctedto-normal vision. We paid 5 Swiss francs (about \$3 US) to each student who served in Experiments 2, 3, and 4. The participants were run in small groups of 6 to 12 students in a computer pool on the campus of the community college. ${ }^{2}$ The experiments were programmed with PsyScope Version 1.2.5 (Cohen et al., 1993) and run on Macintosh iMac computers, with a 15 -in. color monitor running at $60 \mathrm{~Hz}$.

Materials and Procedure. Words and nonwords were the same as in Experiment 1. The procedural details were the same, with two exceptions: First, we now presented black words on a white background, and the mask had $80 \%$ black and $20 \%$ white pixels. Second, 
we introduced the presentation duration condition as a betweensubjects condition. In the short-duration condition, the four levels of presentation duration were $32,48,64$, and $80 \mathrm{msec}$; in the longduration condition, the four levels were 100, 150, 200, and $250 \mathrm{msec}$. The participants had to judge how long the target items were visible on a 9-point scale ranging from 1 (short) to 9 (long).

Statistical analysis. The experimental setup in Experiments 2, 3 , and 4 resulted in a three-factorial design, with the first factor being the presentation group (short vs. long), manipulated between participants. The second factor was the physical dimension that the participants had to judge. We manipulated stimulus duration in Experiment 2, figure-ground contrast in Experiment 3, and letter size in Experiment 4. The participants always had to judge four conditions of the physical dimension. The third factor was stimulus type, either word or nonword. We again report the within-subjects repeated contrasts for the physical dimension in question (duration, contrast, or letter size), comparing Level 1 with Level 2, Level 2 with Level 3, and Level 3 with Level 4, and simple contrasts for stimulus type (word vs. nonword).

For each experiment, we first report the effects of the physical dimension (duration, in this experiment) on judgments and then proceed along the three questions outlined above: (1) We report the effect of stimulus type and discuss the word-superiority effect on judgment. (2) We then turn to the question of whether the wordsuperiority effect is still present when presentation duration is increased. We therefore report the analysis that assesses the interaction between the presentation duration group and the word-superiority effect; if the interaction is significant, we further assess whether this interaction qualifies the word-superiority main effect. (3) Finally, we report the interactions between stimulus type and the physical dimension in question in order to examine the finding of Reingold and Merikle (1988) that there is no difference in judgments between words and nonwords when presentation duration is short.

\section{Results and Discussion}

Means, standard deviations, mean comparisons between words and nonwords, and estimates of effect size are shown in Table 2.

As outlined above, we performed an ANOVA with the three independent variables: presentation group (short vs. long), objective duration (Level 1 vs. Level 2, Level 2 vs. Level 3, Level 3 vs. Level 4), and stimulus type (word vs. nonword).

There was no significant difference between presentation conditions $[F(1,38)=2.13]$. Duration judgments increased with increasing presentation duration, as expressed by significant differences between subsequent levels of presentation duration [all $F_{\mathrm{S}}(1,38)>81.10$, all $p \mathrm{~s}<.001]$.

More important, the participants judged words to be presented longer than nonwords, as shown by the stimulus type main effect $[F(1,38)=27.70, p<.001]$. This finding again replicated the word-superiority effect found by Reingold and Merikle (1988) and the findings of Experiment 1 . The difference in background color-black in Experiment 1 and white in Experiment 2-did not have an influence on the pattern of results.

If the word-superiority effect for apparent duration were confined to short durations, we would expect a presentation group $\times$ type interaction that qualified the main effect. This interaction was indeed significant $[F(1,38)=$ 7.03, $p=.012$ ], but it did not qualify the main effect: Although the effect size was somewhat smaller for the long-duration group than for the short-duration group ( $r \mathrm{~s}=.686$ and .691 , respectively), the word-superiority effect was observed in both groups $[F \mathrm{~s}(1,19)=16.95$ and 17.41 , both $p s=.001]$. The participants in the shortduration group gave higher judgments to words than did those in the long-duration group $[t(38)=2.21, p=$ $.033]$. There was no such difference for nonwords $[t(38)=$ .35].

If only short durations resulted in nonsignificant differences between words and nonwords, there would be a three-way interaction of presentation group, stimulus type, and duration, especially for the contrast between Duration Level 1 (32 or $100 \mathrm{msec}$, respectively) and Duration Level 2 (48 or $150 \mathrm{msec}$, respectively). If, however, the participants had adapted their judgments to the range of the physical dimension, we would observe a two-way interaction of stimulus type and physical dimension for the same contrast without a moderating effect of the presentation duration group. Neither of the three-way interactions was significant $\left[F_{\mathrm{s}}(1,38)<1.65\right]$. The interaction between duration and stimulus type was significant for the contrast between Duration Level 1 and Duration Level $2[F(1,38)=7.26, p=.010]$, but not for the other two contrasts $\left[F_{\mathrm{s}}(1,38)<1.22\right]$. As the rightmost column in Table 2 shows, the effect size for the word-nonword difference was smallest when stimuli were presented for 32 or $100 \mathrm{msec}$. The word-nonword difference was not significant for the latter duration. As

Table 2

Means and Standard Deviations for Duration Ratings for Words and Nonwords, $t$ values and Error Probabilities, and Effect Size $r$ for Each Exposure Duration Condition, by Group

\begin{tabular}{|c|c|c|c|c|c|c|c|c|}
\hline \multirow[b]{2}{*}{ Group } & \multirow{2}{*}{$\begin{array}{c}\text { Time } \\
\text { (in msec) }\end{array}$} & \multicolumn{2}{|c|}{ Word } & \multicolumn{2}{|c|}{ Nonword } & \multirow[b]{2}{*}{$t$} & \multirow[b]{2}{*}{$p$} & \multirow[b]{2}{*}{$r$} \\
\hline & & $M$ & $S D$ & $M$ & $S D$ & & & \\
\hline \multirow[t]{4}{*}{ Short } & 32 & 3.71 & .96 & 3.27 & .74 & 2.35 & .030 & .475 \\
\hline & 48 & 4.56 & .90 & 3.86 & .66 & 3.45 & .003 & .620 \\
\hline & 64 & 5.34 & 1.01 & 4.60 & .69 & 3.31 & .004 & .605 \\
\hline & 80 & 6.13 & 1.12 & 5.08 & .87 & 4.93 & $<.001$ & .750 \\
\hline \multirow[t]{4}{*}{ Long } & 100 & 2.53 & .60 & 2.47 & .62 & .79 & .440 & .179 \\
\hline & 150 & 4.18 & .92 & 3.81 & .90 & 3.42 & .003 & .617 \\
\hline & 200 & 4.86 & 1.05 & 4.58 & 1.06 & 2.26 & .036 & .460 \\
\hline & 250 & 5.90 & 1.17 & 5.65 & 1.21 & 3.35 & .003 & .609 \\
\hline
\end{tabular}

Note- $d f=19$ for the short-duration group and $d f=19$ for the long-duration group. 
in Experiment 1, we found that participants judged words shown for $32 \mathrm{msec}$ to be shown longer than nonwords shown for the same duration. Therefore, we found a word-superiority effect on judged duration even for the lowest duration that Reicher (1969) used.

In Experiment 2, we have shown that participants judged words to be presented for a longer duration than that for nonwords. Moreover, a significant interaction between stimulus type and duration indicated a smaller difference between words and nonwords when objective presentation duration was short in both conditions ( 32 or $100 \mathrm{msec}$ ). The most plausible explanation for this result is that participants first had to adapt to the duration range. They then compared the duration of a presented stimulus with this adaptation level, judging duration of a stimulus as relatively short when it was below this level and as relatively long when it was above adaptation level (see Helson, 1964). As duration judgments increase with objective duration, the differences in judgments increase with increasing duration. Effects of range of duration, combined with the increase in duration estimates, may therefore result in lower differences at the lower end of the range used in the experiment. However, our conclusions have to be taken with some caution because the duration groups did not only differ in duration (short vs. long), but also in the spread of durations; this is much higher for the group with the longer durations $(50 \mathrm{msec}$ between subsequent levels) than for the group with the shorter durations (16 msec between subsequent levels).

\section{EXPERIMENT 3}

In this experiment, we examined judgments of figureground contrast. Repeated exposure has been shown to result in judgments of higher clarity (Masson \& Caldwell, 1998; Whittlesea et al., 1990). We extend these findings by manipulating processing fluency with words and nonwords.

\section{Method}

Thirty-six students of a Swiss community college participated in this experiment, 19 in the short-duration group and 17 in the long- duration group. All other features of the participants and the experimental setting were as in Experiment 2.

The materials and general procedure were the same as in Experiment 2 . In this experiment, we manipulated the figure-ground contrast of the target items $(60 \%, 65 \%, 70 \%$, and $75 \%$ black on the CMYK scale) on a white background. The participants had to rate the darkness of the target items on a 9-point scale ranging from 1 (bright) to 9 (dark). The size of the target items was held constant at 24 points; the presentation duration was set at $48 \mathrm{msec}$ for the short-duration group and at $200 \mathrm{msec}$ for the long-duration group.

\section{Results and Discussion}

Means, standard deviations, mean comparisons between words and nonwords, and estimates of effect size are shown in Table 3.

We performed an ANOVA with the three independent variables of presentation group, figure-ground contrast ( $60 \%$ vs. $65 \%, 65 \%$ vs. $70 \%, 70 \%$ vs. $75 \%$ ), and stimulus type (word vs. nonword).

There was no significant difference between presentation conditions $[F(1,34)=1.44]$. Contrast judgments increased with increasing figure-ground contrast, as expressed by significant differences between subsequent levels of figure-ground contrast [all $F_{\mathrm{s}}(1,34)>45.75$, all $p$ s $<.001]$.

More important, the participants judged words to be presented with more contrast than that for nonwords, as shown by the stimulus type main effect $[F(1,34)=16.46$, $p<.001]$. This finding extended the word-superiority effect found in the previous experiments. It suggests that faster processing of words, which resulted in a feeling of higher fluency, was attributed to the physical dimension we manipulated, in this case figure-ground contrast.

If the word-superiority effect for apparent figureground contrast were confined to short durations, we would expect a group $\times$ type interaction, as observed in Experiment 2. However, this interaction was no longer significant $[F(1,34)=.57]$, suggesting that the wordsuperiority effect is not greater when stimulus presentation is suboptimal.

If only short durations resulted in nonsignificant differences, there would be a three-way interaction of presentation group, stimulus type, and figure-ground contrast

Table 3

Means and Standard Deviations for Contrast Ratings for Words and Nonwords, $t$ values and Error Probabilities, and Effect Size $\boldsymbol{r}$ for Each Exposure Contrast Condition and Exposure Time

\begin{tabular}{|c|c|c|c|c|c|c|c|c|}
\hline \multirow[b]{2}{*}{ Group } & \multirow[b]{2}{*}{ Contrast $(\%)$} & \multicolumn{2}{|c|}{ Word } & \multicolumn{2}{|c|}{ Nonword } & \multirow[b]{2}{*}{$t$} & \multirow[b]{2}{*}{$p$} & \multirow[b]{2}{*}{$r$} \\
\hline & & $M$ & $S D$ & $M$ & $S D$ & & & \\
\hline \multirow[t]{4}{*}{$48 \mathrm{msec}$} & 60 & 5.19 & 1.14 & 5.15 & .97 & .25 & .807 & .055 \\
\hline & 65 & 5.74 & .87 & 5.41 & .94 & 3.22 & .005 & .605 \\
\hline & 70 & 6.02 & .78 & 5.57 & .76 & 3.03 & .007 & .581 \\
\hline & 75 & 6.27 & .58 & 5.99 & .75 & 2.01 & .060 & .428 \\
\hline \multirow[t]{4}{*}{$200 \mathrm{msec}$} & 60 & 3.94 & 1.58 & 4.00 & 1.53 & -.70 & .497 & .170 \\
\hline & 65 & 4.63 & 1.57 & 4.46 & 1.44 & 1.73 & .103 & .397 \\
\hline & 70 & 5.82 & 1.22 & 5.51 & 1.47 & 2.24 & .040 & .488 \\
\hline & 75 & 7.03 & .95 & 6.71 & 1.15 & 1.88 & .078 & .425 \\
\hline
\end{tabular}

Note $-d f=18$ for the 48 -msec group and $d f=16$ for the 200 -msec group; exposure contrast is percentage of black pixels. 
for the statistical contrast analysis between the $60 \%$ and $65 \%$ conditions. If, however, the participants had adapted their judgments to the range of the physical dimension, we would have seen a two-way interaction of stimulus type and physical dimension for the same contrast without a moderating effect of the presentation duration group. Neither of the three-way interactions was significant $\left[F_{\mathrm{s}}(1,34)<.48\right]$. The interaction between figureground contrast and stimulus type was significant in the contrast analysis between the $60 \%$ condition and the $65 \%$ condition $[F(1,34)=6.41, p=.016]$, but not in the other two contrast analyses $\left[F_{\mathrm{s}}(1,34)<1.25\right]$. As the rightmost column in Table 3 shows, the effect size for the word-nonword difference was smallest when stimuli were presented with a contrast of $60 \%$. Unlike in Experiment 2, the spread of figure-ground contrast was the same for both duration groups, so we can be more certain in explaining the results in terms of adaptation to the range of the stimulus dimension, figure-ground contrast in this experiment.

In sum, we were able to extend the findings on judged duration to judged figure-ground contrast, adding further evidence to the notion that perceptual fluency due to the word-nonword distinction was attributed to the physical dimension we manipulated.

\section{EXPERIMENT 4}

Experiment 4 was identical to Experiment 3, with the exception that the manipulated and judged physical dimension was letter size instead of figure-ground contrast. Replicating the findings of Experiment 3 would extend existing evidence to size judgments.

\section{Method}

Forty-three students of a Swiss community college participated in this experiment, 22 in the short-duration group and 21 in the long-duration group. All other features of the participants and the experimental setting were as in Experiments 2 and 3.

Materials and general procedure were the same as in Experiments 2 and 3 . In this experiment, we manipulated the size of the target items $(12,13,14$, or 15 points). The participants had to rate the size of the target items on a 9-point scale ranging from 1 (small) to 9 (large). Target items were black on a white background; the presentation duration was set at $48 \mathrm{msec}$ for the short-duration group and at $200 \mathrm{msec}$ for the long-duration group.

\section{Results and Discussion}

Means, standard deviations, mean comparisons between words and nonwords, and estimates of effect size are shown in Table 4.

We performed an ANOVA with the three independent variables of presentation group, size (12 vs. 13 points, 13 vs. 14 points, 14 vs. 15 points), and stimulus type (word vs. nonword).

There was no significant difference between presentation conditions $[F(1,41)=0.15]$. Size judgments increased with increasing letter size, as expressed by significant differences between subsequent levels of letter size [all $F_{\mathrm{s}}(1,41)>61.72$, all $\left.p \mathrm{~s}<.001\right]$.

More important, participants judged words to be presented in greater size than nonwords, as shown by the stimulus type main effect $[F(1,41)=64.21, p<.001]$. This finding extended the word-superiority effect found in the previous experiments. Again, faster processing of the words resulted in a feeling of higher fluency that was attributed to the physical dimension we assessed, letter size in this experiment.

If the word-superiority effect for apparent figureground contrast were confined to short durations, we would expect a group $\times$ type interaction. As in Experiment 3, this interaction was no longer significant $[F(1,41)=$ $.08]$, suggesting that the word-superiority effect is not greater when stimulus presentation is suboptimal.

If only short durations resulted in nonsignificant differences, there would be a three-way interaction of presentation group, stimulus type, and letter size for the contrast between 12 and 13 points. If, however, participants had adapted their judgments to the range of the physical dimension, we would have seen a two-way interaction of stimulus type and physical dimension for the same contrast without a moderating effect of the presentation duration group. We replicated the pattern of results from Experiments 2 and 3. Neither of the three-way interactions was significant $\left[F_{\mathrm{s}}(1,41)<1.49\right]$. The interaction between size and stimulus type was significant for the contrast between the 12-point condition and the 13-point

Table 4

Means and Standard Deviations for Size Ratings for Words and Nonwords, $t$ Values and Error Probabilities, and Effect Size $\boldsymbol{r}$ for Each Exposure Size Condition and Exposure Time

\begin{tabular}{|c|c|c|c|c|c|c|c|c|}
\hline \multirow[b]{2}{*}{ Time } & \multirow{2}{*}{$\begin{array}{c}\text { Size } \\
\text { (in points) }\end{array}$} & \multicolumn{2}{|c|}{ Word } & \multicolumn{2}{|c|}{ Nonword } & \multirow[b]{2}{*}{$t$} & \multirow[b]{2}{*}{$p$} & \multirow[b]{2}{*}{$r$} \\
\hline & & $M$ & $S D$ & $M$ & $S D$ & & & \\
\hline \multirow[t]{4}{*}{$48 \mathrm{msec}$} & 12 & 3.18 & .86 & 3.05 & .84 & 1.52 & .144 & .315 \\
\hline & 13 & 4.77 & 1.18 & 4.51 & .99 & 2.91 & .008 & .536 \\
\hline & 14 & 5.28 & .99 & 5.05 & 1.01 & 3.12 & .005 & .562 \\
\hline & 15 & 5.73 & 1.05 & 5.34 & 1.10 & 3.85 & $<.001$ & .643 \\
\hline \multirow[t]{4}{*}{$200 \mathrm{msec}$} & 12 & 2.07 & .79 & 1.92 & .65 & 2.40 & .026 & .473 \\
\hline & 13 & 4.31 & .96 & 3.95 & 1.03 & 4.78 & $<.001$ & .730 \\
\hline & 14 & 5.88 & .87 & 5.57 & .78 & 3.02 & .007 & .560 \\
\hline & 15 & 6.34 & .88 & 6.09 & .78 & 2.55 & .019 & .495 \\
\hline
\end{tabular}

Note- $d f=21$ for the 48 -msec group, and $d f=20$ for the 200 -msec group. 
condition $[F(1,41)=4.39, p=.042]$, but not for the other two contrasts $[F \mathrm{~s}(1,41)<.26]$. As the rightmost column in Table 4 shows, the effect size for the wordnonword difference was smallest when stimuli were presented with a size of 12 points.

The first four experiments have extended the existing database. We have demonstrated a word-superiority effect on judgments of time, contrast, and size even when stimuli were presented for more than $100 \mathrm{msec}$. The fifth experiment was designed to examine the role of expected fluency on judgments of duration.

\section{EXPERIMENT 5}

In recent years, the role of expectation and attribution in moderating the effects of fluency on judgments has been examined (Westerman, Lloyd, \& Miller, 2002; Whittlesea \& Williams, 1998, 2000, 2001). Whittlesea and Williams (1998), for example, demonstrated that enhanced perceptual fluency does not necessarily result in higher familiarity. They used words, regular nonwords, and irregular nonwords as stimuli. Regular nonwords had no meaning in English, but were nonetheless easy to read, such as HENSION or WIMBER. Irregular nonwords were difficult to read, such as STOFWUS or OUETIS. The participants were shown words, regular nonwords, and irregular nonwords in a training phase. In a subsequent test phase, the participants were shown old and new stimuli from each of the three categories and had to perform three tasks on each stimulus: First, they had to pronounce it, then decide if it was a word or a nonword, and finally to decide if it had been presented in training. Processing fluency, as measured by pronunciation latency and lexical decision, was higher for words than for regular nonwords and higher for regular nonwords than for irregular nonwords. If processing fluency alone determined the proportion of false alarms in the recognition test, words would yield more false alarms than regular nonwords, which, in turn, would yield more false alarms than irregular nonwords. However, regular nonwords produced more false alarms than did words and irregular nonwords, respectively. Whittlesea and Williams concluded that not processing fluency per se, but the discrepancy between expected and actual fluency resulted in an increase in positive recognition judgments. It is not surprising that words can be processed fluently, whereas irregular nonwords cannot. Therefore, fluent processing of words is attributed to the fact that the stimuli are words, not to familiarity. However, fluent processing of regular nonwords comes as a surprise because there is a discrepancy between expected and actual fluency. This unexplained fluency is attributed to familiarity, increasing the proportion of false alarms. In Experiment 5, we examined whether this logic applied to perceptual judgments, such as those used in our previous experiments.

If, for example, perceived duration depended on a discrepancy between expected and actual fluency, one would expect regular nonwords to be judged as shown longer than words and irregular nonwords, respectively. As in the Whittlesea and Williams (1998) study discussed above, it is not surprising that words are processed fluently, whereas irregular nonwords are not. It may be unexpected, however, that regular nonwords are processed fluently, thus increasing perceived duration.

Whereas some biases in judgments disappear when people become aware of the extraneous source of fluency or when there is a discrepancy between expected and actual fluency, other sources seem impenetrable (see Kelley \& Rhodes, 2002), and people continue to base their judgment on processing fluency. In the study by Whittlesea and Williams (1998), participants presumably distinguished between the sources of fluency and could construct expectations for each source of fluency. Because they did not expect high fluency from (regular) nonwords, they attributed to familiarity that part of experienced fluency that actually was caused by the ease of pronouncing regular nonwords. If participants had not been able to distinguish the two sources of fluency, they would not have constructed expectations for the ease of processing words and nonwords, but would have directly attributed fluency to familiarity. In duration judgments, for example, participants may not be able to distinguish between processing fluency due to objective duration and processing fluency due to wordnonword manipulation; they may therefore continue to attribute fluency to perceived duration. If so, one would expect words to be judged shown longer than regular nonwords, which, in turn, get higher duration judgments than irregular nonwords. We addressed this issue in Experiment 5 by adding 96 regular nonwords to the materials we used in the previous experiments.

\section{Method}

Forty-nine undergraduate students of a Swiss university participated in this experiment. The participants were tested individually in a laboratory room.

Materials and Procedure. Materials and general procedure were exactly the same as in Experiment 1, with the exception that there were black letters on a white background, as in Experiments 2-4. Most important, we added a set of 96 regular nonwords that was created by rearrangement of letters of the words used in all experiments. Like the irregular nonwords, the regular nonwords were meaningless. In contrast to the irregular nonwords, the regular nonwords were orthographically more regular in German and were thus easier to read and pronounce. In order to test this assumption, we assessed identification latencies and errors.

Identification latencies and errors. Nineteen undergraduate students who did not participate in the main experiment were presented with the stimulus material and were instructed to press a key as soon as they were able to identify the stimulus and to type the stimulus on the keyboard. We measured identification latency; we asked the participants to type the stimulus in order to assess accuracy of word identification. The results on this task were clear cut. We present means and standard deviations for the data averaged over all the participants in the two upper rows of Table 5: Both latencies and errors differed for the three groups, as analyzed with repeated contrasts $[$ all $F \mathrm{~s}(1,18)>18.45]$, and effect sizes were considerable, as the two rightmost columns of Table 5 show. 
Table 5

Means and Standard Deviations for Duration Ratings for Words, Regular Nonwords, and Irregular Nonwords, for Each Exposure Duration Condition

\begin{tabular}{|c|c|c|c|c|c|c|c|c|}
\hline \multirow{2}{*}{$\begin{array}{c}\text { Time } \\
\text { (in msec) }\end{array}$} & \multicolumn{2}{|c|}{ Word } & \multicolumn{2}{|c|}{ Regular Nonwords } & \multicolumn{2}{|c|}{ Irregular Nonwords } & \multirow[b]{2}{*}{$r_{1}$} & \multirow[b]{2}{*}{$r_{2}$} \\
\hline & $M$ & $S D$ & $M$ & $S D$ & $M$ & $S D$ & & \\
\hline \multicolumn{9}{|l|}{ Identification } \\
\hline Latencies & 519 & 103 & 1,000 & 406 & 1,770 & 910 & .83 & .82 \\
\hline Errors & .11 & .32 & 1.32 & 1.25 & 4.21 & 3.12 & .71 & .74 \\
\hline \multicolumn{9}{|c|}{ Duration ratings } \\
\hline 32 & 3.74 & 1.02 & 3.27 & .75 & 3.06 & .74 & .59 & .45 \\
\hline 48 & 4.51 & 1.01 & 3.93 & .75 & 3.64 & .81 & .61 & .55 \\
\hline 64 & 5.34 & 1.06 & 4.71 & .70 & 4.37 & .71 & .57 & .54 \\
\hline 80 & 6.26 & 1.11 & 5.40 & .97 & 5.09 & .87 & .72 & .50 \\
\hline
\end{tabular}

Note $-r_{1}=$ effect size $r$ for contrast between words and regular nonwords; $r_{2}=$ effect size $r$ for contrast between regular nonwords and irregular nonwords.

\section{Results and Discussion}

Means, standard deviations, and estimates of the size of effects for the comparisons of words with regular nonwords, and of regular nonwords with irregular nonwords, respectively, are shown in the last four rows of Table 5. All $t$ tests for the pairwise comparisons of words to regular nonwords and of regular nonwords to irregular nonwords were significant [all $t \mathrm{~s}(48)>3.45$, all $p \mathrm{~s}<.005$ ].

We performed an ANOVA with the two independent variables of duration ( $32 \mathrm{vs} .48 \mathrm{msec}, 48$ vs. $64 \mathrm{msec}, 64$ vs. $80 \mathrm{msec}$ ) and stimulus type (word vs. regular nonword, regular nonword vs. irregular nonword). Duration increased with increasing presentation duration, as expressed by significant differences between subsequent levels of presentation duration [all $F \mathrm{~s}(1,48)>125.17$, all $p$ s $<.001]$.

More important, the two contrasts including stimulus type showed that the participants judged words to be presented longer than regular nonwords $[F(1,48)=43.79$, $p<.001]$, which, in turn, were judged to be presented longer than irregular nonwords $[F(1,48)=65.42, p<$ $.001]$. This result suggests that -in contrast to the predictions of the discrepancy-attribution hypothesis - the participants did not distinguish between the contributions of actual duration and the word-nonword distinction to perceived duration and therefore continued to base their duration judgments on experienced processing fluency.

If the participants had adapted their judgments to the range of the physical dimension, we would have seen a two-way interaction of stimulus type and physical dimension for the contrast between 32 and $48 \mathrm{msec}$. In order to compare the result with those of the former experiments, we performed a further analysis, this time only with words and irregular nonwords. The interaction between duration and stimulus type was significant for the contrast between 32 and $48 \mathrm{msec}[F(1,48)=4.28$, $p=.044]$, but not for the contrast between 48 and $64 \mathrm{msec}$ $[F(1,48)=.69]$. Unlike in the previous experiments, the interaction was also significant for the contrast between 64 and $80 \mathrm{msec}[F(1,48)=4.97, p=.031]$. As in the previous experiments, the effect size for the comparison of words with irregular nonwords was lowest for the shortest objective duration ( $r \mathrm{~s}=.66, .69, .70$, and .77 , respectively). This suggests that the participants first adapted to the duration range in order to make their judgments.

\section{GENERAL DISCUSSION}

In five experiments, we have shown that the more fluent processing of words in comparison with irregular nonwords results in judgments of longer duration, higher contrast, and larger letter size. The superiority in apparent duration of words over irregular nonwords in Experiments 1 and 2 supports the notion that perceptual fluency is related to judgments of higher duration, as found in the studies of Reingold and Merikle (1988), Whittlesea (1993), and Witherspoon and Allan (1985). As outlined by Reingold and Merikle, some methodological differences may account for the inconsistencies between the findings of Avant et al. (1975) and others. In sum, we were able to show that on average, words were judged as being presented for a longer duration than were irregular nonwords shown for the same objective duration. Since we used a time range from 32 to $250 \mathrm{msec}$, our findings fit the notion that more fluent processing of words compared with irregular nonwords, as shown by Reicher (1969), results in higher apparent duration.

Prinzmetal (1992; Prinzmetal \& Silvers, 1994) found word-superiority effects on letter discrimination when the stimuli were present until the participants reacted. Consistent with this finding, we were able to demonstrate a word-superiority effect on phenomenal experience of duration for objective durations that were longer than those used by Reicher (1969).

There are several possible explanations for why participants process words more fluently than nonwords. Most studies discussed such effects in terms of higher stimulus familiarity for words rather than nonwords. Marohn and Hochhaus (1988), however, found that semantic priming increased and repetition priming decreased apparent stimulus duration. This finding suggests that fluent processing of words-compared with nonwords - may be due to semantic factors rather than 
repeated exposure. In the present study, we have distinguished two sources of processing fluency, actual duration and the word-nonword distinction, without disentangling the sources of fluency due to the latter source.

In Experiments 3 and 4, we extended the wordsuperiority effect on judgments of duration to other judgments. More fluent processing of words, in comparison with nonwords, is misattributed to the phenomenal experience of duration, figure-ground contrast, and size.

The pattern of results is highly consistent across the experiments. We found a substantial word-superiority effect for the short- and long-duration conditions, even when there was an interaction between presentation condition and stimulus type, as in Experiment 2. Moreover, the effect size was always smallest for the smallest objective duration, contrast, or size in each presentation condition, a fact also expressed by the significant interactions of type and the contrast between Level 1 and Level 2 of the physical dimension in Experiments 2-5. The increase in differences was not always linear with increasing level of the physical dimension. Therefore, we do not yet fully understand the basis of the repeatedly observed fact that effect sizes were smallest for the smallest duration in each condition. However, this finding sheds light on the findings of Reingold and Merikle (1988): It does not necessarily mean that there is no word-superiority effect on perceived duration for the shortest objective duration; it could well be the consequence of a participant's adaptation to the range of stimulus duration. More generally, any absence of an effect for the smallest size of a physical dimension has to be discussed with caution because it could mean either a real absence of effect or a participant's adaptation to the range of this physical dimension.

In our final experiment, we showed that words were judged as shown longer than regular nonwords, which in turn were judged as being shown longer than irregular nonwords. In contrast to the predictions of a discrepancyattribution hypothesis, participants judged words to be shown longer than regular nonwords, and regular nonwords to be shown longer than irregular nonwords.

Our findings suggest that participants did not distinguish between the two sources of fluency: Actual duration and the word-nonword distinction. Consequently, participants were not taken by surprise at how fluently they could process regular nonwords, and could not allocate a part of fluency to perceived duration judgments that was due to the surprisingly fluent processing of regular nonwords.

Why did participants not distinguish between the two sources of fluency? First, Whittlesea and Williams (1998, $2000,2001)$ used stimulus materials different from ours, so a direct comparison of our study with their studies cannot be performed. Due to the construction of regular nonwords from the German word materials of our previous experiments, regular nonwords were somewhat less regular than those used by Whittlesea and Williams, and irregular nonwords in our study were less regular than those used in their studies. We cannot rule out that such differences may prevent the feeling of surprise from accompanying the fluent processing of regular nonwords. However, the pattern of identification latencies is the same as the pattern of pronunciation latencies in the Whittlesea and Williams experiments, so the studies are comparable at least in that respect.

A second possibility would be that participants were not able to distinguish between the two sources of fluency because fluency due to the word-nonword distinction is impenetrable and cannot be separated from other sources of fluency, such as perceived duration. This assumption is highly improbable, however, because Whittlesea and Williams's $(1998,2000)$ participants were perfectly able to separate fluency due to the word-nonword distinction from fluency due to familiarity and to build expectations of how fluently words, regular nonwords, and irregular nonwords should be processed.

A final, more plausible assumption is that duration judgments and recognition decisions differ in the strategy participants use to solve the task. Recognition involves recollection of memories; fluency plays a dominant role only if conscious recollection fails to yield reliable memories (e.g., Jacoby et al., 1989) and if fluency is seen as a relevant source (e.g., Westerman et al., 2002). Therefore, participants do not necessarily assess experienced fluency immediately and do not infer familiarity directly from experienced fluency. They are aware of the different sources they can use for their recognition judgment and therefore may distinguish different sources of processing fluency. Duration judgments, however, require no more than an assessment of perceptual fluency, even though other sources may be available. Participants can simply transform experienced fluency into a judgment, bypassing any analysis that enables the distinction between different sources of fluency. If this assumption is right, we would see the pattern of results predicted by the discrepancy-attribution hypothesis if experimenters could establish conditions that require more analytical processing for judging durations. If, on the other hand, one could induce participants to base their recognition decisions directly on perceptual fluency, one would observe the pattern of results in our last experiment. In sum, expectations come into play only if people do not infer their judgment from a direct assessment of perceptual fluency.

\section{REFERENCES}

Allan, L. G. (1979). The perception of time. Perception \& Psychophysics, 26, 340-354.

Avant, L. L., \& Lyman, P. J. (1975). Stimulus familiarity modifies perceived duration in precognition visual processing. Journal of Experimental Psychology: Human Perception \& Performance, 1, 205-213.

Avant, L. L., Lyman, P. J., \& Antes, J. (1975). Effects of stimulus familiarity upon judged visual duration. Perception \& Psychophysics, 17, 253-262.

BEGG, I. M., AnAs, A., \& FARINACCI, S. (1992). Dissociation of processes in belief: Source recollection, statement familiarity, and the illusion of truth. Journal of Experimental Psychology: General, 121, 446-458.

Cohen, J. [D.], MacWhinney, B., Flatt, M., \& Provost, J. (1993). PsyScope: An interactive graphic system for designing and control- 
ling experiments in the psychology laboratory using Macintosh computers. Behavior Research Methods, Instruments, \& Computers, 25, $\underline{257-271 .}$

Goldinger, S. D., Kleider, H. M., \& Shelley, E. (1999). The marriage of perception and memory: Creating two-way illusions with words and voices. Memory \& Cognition, 27, 328-338.

Hager, W., \& Hasselhorn, M. (EDS.) (1994). Handbuch deutschsprachiger Wortnormen [Handbook of German word norms]. Göttingen: Hogrefe.

Helson, H. (1964). Adaptation level theory: An experimental and systematic approach to behavior. New York: Harper.

JaCoby, L. L., Allan, L. G., Collins, J. C., \& Larwill, L. K. (1988). Memory influences subjective experience: Noise judgments. Journal of Experimental Psychology: Learning, Memory, \& Cognition, 14, 240-247.

JACOBY, L. L., \& DaLlas, M. (1981). On the relationship between autobiographical memory and perceptual learning. Journal of Experimental Psychology: General, 110, 306-340.

JaCOBY, L. L., Kelley, C. M., BROWN, J., \& JASEChKo, J. (1989). Becoming famous overnight: Limits on the ability to avoid unconscious influences of the past. Journal of Personality \& Social Psychology, 56, 326-338.

KELLEY, C. M., \& JACOBY, L .L. (1996). Adult egocentrism: Subjective experience versus analytic bases for judgment. Journal of Memory \& Language, 35, 157-175.

Kelley, C. M., \& RhODES, M. G. (2002). Making sense and nonsense of experience: Attributions in memory and judgment. In B. Ross (Ed.), The psychology of learning and motivation: Advances in research and theory (Vol. 41, pp. 293-320). New York: Elsevier, Academic Press.

Marohn, K. M., \& Hochhaus, L. (1988). Semantic priming increases and repetition priming decreases apparent stimulus duration. Journal of General Psychology, 115, 51-61.

Masson, M. E. J., \& Caldwell, J. I. (1998). Conceptually driven episodes create perceptual misattributions. Acta Psychologica, $\mathbf{9 8}$, 183-210.

PRINZMETAL, W. (1992). The word-superiority effect does not require a T-scope. Perception \& Psychophysics, 51, 473-484.

Prinzmetal, W., \& Silvers, B. (1994). The word without the tachistoscope. Perception \& Psychophysics, 55, 296-312.

Reber, R., \& SchWARZ, N. (1999). Effects of perceptual fluency on judgments of truth. Consciousness \& Cognition, 8, 338-342.

Reber, R., Winkielman, P., \& SchWarz, N. (1998). Effects of perceptual fluency on affective judgments. Psychological Science, $, \underline{9}, 45-$ 48.

Reber, R., Wurtz, P., \& Zimmermann, T. D. (2004). Exploring "fringe" consciousness: The subjective experience of perceptual fluency and its objective bases. Consciousness \& Cognition, 13, 47-60.

ReICHER, G. M. (1969). Perceptual recognition as a function of meaningfulness of the stimulus material. Journal of Experimental Psychology, 81, 275-280.

REINGOLD, E. M., \& MerIKLE, P. M. (1988). Using direct and indirect measures to study perception without awareness. Perception \& Psychophysics, 44, 563-575.
RuOFF, A. (1981). Häufigkeitswörterbuch gesprochener Sprache [Dictionary of word frequencies in spoken language]. Tübingen: Niemeyer.

Thomas, E. A. C., \& Weaver, W. B. (1975). Cognitive processing and time perception. Perception \& Psychophysics, 17, 363-367.

Tотн, J. P., \& Daniels, K. A. (2002). Effects of prior experience on judgments of normative word frequency: Automatic bias and correction. Journal of Memory \& Language, 46, 845-874.

WARM, J. S., \& MCCRAY, R. E. (1969). Influence of word frequency and length on the apparent duration of tachistoscopic presentations. Journal of Experimental Psychology, 79, 56-58.

Westerman, D. L., Lloyd, M. E., \& Miller, J. K. (2002). The attribution of perceptual fluency in recognition memory: The role of expectation. Journal of Memory \& Language, 47, 607-617.

Whittlesea, B. W. A. (1993). Illusions of familiarity. Journal of Experimental Psychology: Learning, Memory, \& Cognition, 19, 12351253.

Whittlesea, B. W. A., JACOBY, L. L., \& Girard, K. (1990). Illusions of immediate memory: Evidence of an attributional basis for feelings of familiarity and perceptual quality. Journal of Memory \& Language, 29, 716-732.

WhittleseA, B. W. A., \& Williams, L. D. (1998). Why do strangers feel familiar, but friends don't? The unexpected basis of feelings of familiarity. Acta Psychologica, 98, 141-166.

Whittlesea, B. W. A., \& Williams, L. D. (2000). The source of familiarity: The discrepancy-attribution hypothesis. Journal of Experimental Psychology: Learning, Memory, \& Cognition, 26, 547-565.

Whittlesea, B. W. A., \& Williams, L. D. (2001). The discrepancyattribution hypothesis: I. The heuristic basis of feelings of familiarity. Journal of Experimental Psychology: Learning, Memory, \& Cognition, 27,3-13.

WinkIELMAN, P., SchWARZ, N., FAZENDEIRo, T. A., \& Reber, R. (2003). The hedonic marking of processing fluency: Implications for evaluative judgment. In J. Musch \& K. C. Klauer (Eds.), The psychology of evaluation: Affective processes in cognition and emotion (pp. 189217). Mahwah, NJ: Erlbaum.

Witherspoon, D., \& Allan, L. G. (1985). The effect of a prior presentation on temporal judgments in a perceptual identification task. Memory \& Cognition, 13, 101-111.

\section{NOTES}

1. We did not analyze linear trends because increase in judgment was not linear. The advantage of repeated contrasts was that we were able to determine where there were interactions with the stimulus type condition.

2. In this computer pool, there was one computer per three seats so that the distance between two computers was about $2 \mathrm{~m}$. Therefore, the participants were not able to see one another's screen or to lean over to each other's computer. Moreover, the participants started the experiment together, and they were instructed to wait until all had finished the experiments.

(Manuscript received December 23, 2002; revision accepted for publication December 16, 2003.) 